\title{
Extracellular Proton Release by Stimulated Neutrophils
}

\author{
Rob van Zwieten, Ron Wever, Mic N. Hamers, Ron S. Weening, and Dirk Roos, \\ Central Laboratory of the Netherlands Red Cross Blood Transfusion \\ Service and Laboratory for Experimental and Clinical Immunology, \\ B. C. P. Jansen Institute, Laboratory of Biochemistry, University of Amsterdam, \\ Amsterdam; and Pediatric Clinic, Binnengasthuis, University Hospital of \\ Amsterdam, Amsterdam, The Netherlands
}

A B S T R A C T We have tried to elucidate the mechanism of phagosome acidification in human neutrophils. Assuming that phenomena occurring at the plasma membrane reflect reactions in the phagocytic vacuoles, we have stimulated human neutrophils with agents that induce a "respiratory burst," and we have measured the release of protons into the extracellular medium. Phorbol myristate acetate, $\mathrm{N}$-formyl-methionyl-leucyl-phenylalanine and serum-opsonized $\mathrm{zy}$ mosan particles each caused a rapid release of protons, concomitant with the increase in oxygen consumption. The stimulated release of protons was strictly coupled to the increased respiration of the cells, because inhibition of the respiration by either anaerobiosis, chlorpromazine, or glycolytic inhibitors also inhibited the release of protons. Also, in the presence of the above-mentioned stimulating agents, neutrophils from three patients with chronic granulomatous disease enhanced neither respiration nor proton release. In normal cells, the ratio of $\Delta \mathrm{H}^{+} /-\Delta \mathrm{O}_{2}$ was $1.04 \pm 0.19$ (mean $\pm \mathrm{SD}, n=13$ ).

The mechanism of this proton release is not clear. The amount of lactic and carbonic acid produced by stimulated neutrophils was inadequate to explain the amount of protons released. Perhydroxyl radicals were also ruled out as the source of the protons. Because the cells did not release measurable amounts of phosphate ions, a phosphate-hydroxyl-ion antiport was also excluded. Finally, the lack of any effect of uncouplers renders it unlikely that a respiration-driven proton gradient is built up across the plasma membrane.

\section{INTRODUCTION}

During phagocytosis, neutrophilic granulocytes (neutrophils) exhibit a burst of metabolic activity. This "respiratory burst" is characterized by an increased

Received for publication 24 March 1981 and in revised form 13 May 1981. oxygen consumption (nonmitochondrial) and hexose monophosphate shunt activity (1). The latter process supplies NADPH, which is used to reduce oxygen to hydrogen peroxide by an "NADPH-oxidase system" in the plasma membrane (2). This oxidase is inactive in resting cells, but it is activated by particle attachment. Thus, ingested microorganisms are engulfed by a section of $\mathrm{H}_{2} \mathrm{O}_{2}$-secreting plasma membrane (the phagosome).

During and shortly after phagosome formation, neutrophilic granules fuse with and discharge their contents into the phagosomes. In this way, myeloperoxidase (from azurophilic granules) is brought into contact with $\mathrm{H}_{2} \mathrm{O}_{2}$ and chloride, resulting in generation of highly microbicidal agents (3). Other antimicrobial proteins, from both the azurophilic and the specific granules, are also released into the phagosomes, e.g., cationic proteins, acid hydrolases, lysozyme, lactoferrin, etc. (for a review, see ref. 4). Many of these enzymes have acid pH optima, and it is well documented that the $\mathrm{pH}$ in the phagocytic vacuoles becomes acid (5-7).

The mechanism of this acidification is still unknown. Mandell (5) has shown that sodium fluoride, iodoacetate, and refrigeration inhibit the acidification of the phagolysosomes and suggested, therefore, that lactate, produced during phagocytosis, might cause the drop in $\mathrm{pH}$. Allen (8) proposed that the NADPH-oxidase system might produce perhydroxyl radicals $\left(\cdot \mathrm{O}_{2} \mathrm{H}\right)$, which subsequently split into superoxide radicals $\left(\cdot \mathrm{O}_{2}^{-}\right)$and protons. Because the $\mathrm{pK}_{\mathrm{a}}$ of this dissociation is 4.8 , this reaction might also explain the decrease in the phagosomal pH. Finally, Cline (9) suggested the existence of a proton-translocating system in the phagosomal membrane. This system might pump protons into the phagosomes by the reaction of carbonic anhydrase with water and $\mathrm{CO}_{2}$ (generated in the hexose monophosphate shunt).

Assuming that phenomena occurring at the exterior of a neutrophil reflect the intraphagosomal situation 
(because the plasma membrane folds inside-out around a particle to form a phagosome), we have measured the release of protons from these cells into the extracellular medium. Our results show that this process is strictly linked to the oxygen consumption of the neutrophils, on a mole-to-mole basis with the activated respiration. As to the mechanism of this proton release, however, we have as yet no explanation but seriously question the above-mentioned proposals for the phagosome acidification.

\section{METHODS}

Venous blood was collected from healthy donors and from three patients with chronic granulomatous disease (CGD). ${ }^{1}$ Neutrophils were isolated according to described methods (10). The neutrophils were suspended in phosphate-buffered saline (10 mM phosphate, $140 \mathrm{mM} \mathrm{NaCl}, \mathrm{pH} 7.2$ ), containing $\mathrm{CaCl}_{2}(0.6 \mathrm{mM}), \mathrm{MgCl}_{2}(1 \mathrm{mM})$, glucose $(5.5 \mathrm{mM})$, and human albumin $(0.5 \%$, wt/vol). The cell preparations contained $90-95 \%$ neutrophils.

The neutrophils were stimulated with phorbol myristate acetate (PMA, Consolidated Midland Corp., Brewster, N. Y.) in a final concentration of $100 \mathrm{ng} / \mathrm{ml}$, with serum-treated zymosan (11) at $1 \mathrm{mg} / \mathrm{ml}$, or with $N$-formyl-methionylleucyl-phenylalanine at $1 \mathrm{nM}$.

Lactate production was measured according to described methods (12) in 30-fold diluted samples taken from neutrophil incubations $\left(1.5 \times 10^{7}\right.$ cells $\left./ \mathrm{ml}\right)$ at $37^{\circ} \mathrm{C}$. Hexose monophosphate (HMP) shunt activity was assayed as ${ }^{14} \mathrm{CO}_{2}$ production from $\left[1{ }^{14} \mathrm{C}\right]$ glucose (Amersham, Bucks., UK) as described (13) $\left(3 \times 10^{6}\right.$ cells $\left./ \mathrm{ml}, 37^{\circ} \mathrm{C}\right)$. Oxygen consumption was measured with an oxygen electrode (10) and proton release with a combined glass reference electrode (Ingold, type 10405 3032, Urdorf, West Germany) in the same cell suspension $\left(3 \times 10^{6}\right.$ cell $\left./ \mathrm{ml}\right)$ at $37^{\circ} \mathrm{C}$. In this assay, $1 \mathrm{mM}$ phosphate buffer ( $\mathrm{pH} 7.2$ ) was used, containing $140 \mathrm{mM} \mathrm{NaCl}, 0.6 \mathrm{mM}$ $\mathrm{CaCl}_{2}, 1 \mathrm{mM} \mathrm{MgCl}, 5.5 \mathrm{mM}$ glucose, and $2 \mathrm{mM} \mathrm{NaN}_{3}$. The proton-release measurement was calibrated by adding known amounts of oxalic acid to the incubation mixture. The $\mathrm{NaN}_{3}$ was added to prevent regeneration of oxygen via the reaction of catalase with hydrogen peroxide. The amount of azide used in this assay did not interfere with the $\mathrm{pH}$ measurement. Lactate production, HMP shunt activity, oxygen consumption, and proton release were assayed in parallel incubations with cells from the same blood donation.

\section{RESULTS AND DISCUSSION}

A typical experiment in which oxygen consumption and proton release were measured in the same cell suspension is shown in Fig. 1. Resting normal neutrophils showed a low oxygen consumption and little proton release (Fig. 1A). Upon stimulation with PMA, both processes increased simultaneously and returned to basal levels $\sim 10 \mathrm{~min}$ later. Similar results were obtained with neutrophils treated with $N$-formyl-methionyl-leucyl-phenylalanine or with opsonized zymosan particles (not shown). Anaerobiosis or addition of

${ }^{1}$ Abbreviations used in this paper: CGD, chronic granulomatous disease; HMP, hexose monophosphate; PMA, phorbol myristate acetate.

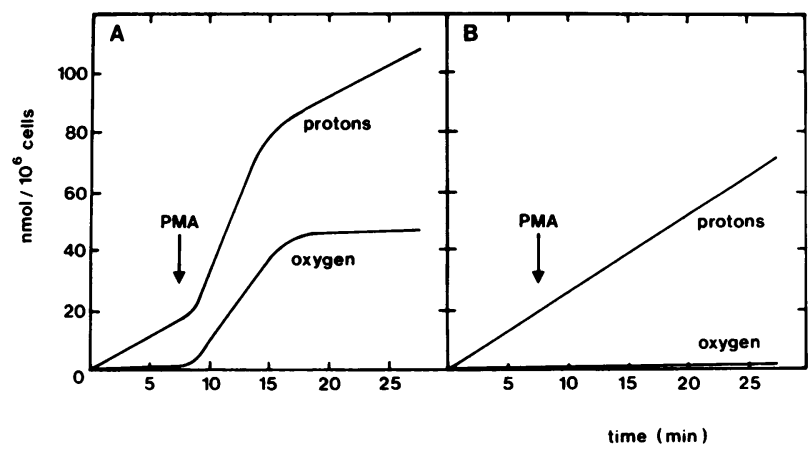

Figure 1 Oxygen consumption and proton release by human neutrophils. A, neutrophils from a normal donor; B, neutrophils from a patient with CGD.

chlorpromazine $(100 \mu \mathrm{M})$, an inhibitor of the NADPHoxidase system (14), inhibited both the oxygen consumption and the stimulated proton release (not shown).

Neutrophils from three patients with CGD, which lack the respiratory burst phenomena (15), also failed to show a stimulation of the proton release (Fig. 1B). This suggests that the stimulated proton release is coupled to the oxygen consumption, to the HMP shunt, or to both.

Proton release can be caused either by release of neutral products that dissociate into protons and anions in the extracellular medium, by establishment of a proton gradient across the plasma membrane, or by an hydroxyl-ion-anion antiport across the plasma membrane. Because it is known that neutrophils produce lactate via glycolysis and bicarbonate via the HMP shunt (1), we measured these products in resting and stimulated normal and CGD neutrophils, in parallel with the oxygen consumption and proton release. The results are shown in Table I. The protons released in the resting state can be accounted for by the lactate produced, whereas the protons released in the stimulated state cannot be accounted for by lactate plus bicarbonate, except in CGD neutrophils. Furthermore, in normal neutrophils, the amount of protons released (corrected for lactate and bicarbonate production) was found to be equal to the amount of extra oxygen consumed in the stimulated state. In 13 separate experiments, a mean $\Delta \mathrm{H}^{+} /-\Delta \mathrm{O}_{2}$ ratio of 1.04 was found (range, 0.58-1.34; SD 0.19). This strongly suggests that a respiration-linked proton translocation exists. Indeed, inhibitors of glycolysis, such as mono-iodoacetic acid $(5 \mathrm{mM})$, sodium fluoride $(10 \mathrm{mM})$, or 2deoxyglucose $(25 \mathrm{mM})$, abolished the proton release and the oxygen consumption both in resting and in stimulated cells (not shown).

Another product of neutrophils that might split into anions and protons could be perhydroxyl radicals $\left[\cdot \mathrm{O}_{2} \mathrm{H}\right.$, in equilibrium with superoxide radicals $\left(\cdot \mathrm{O}_{2}^{-}\right)$ 
TABLE I

Acid Production and Oxygen Consumption in Human Neutrophils

\begin{tabular}{|c|c|c|c|c|c|c|}
\hline \multirow[b]{2}{*}{ Parameter } & \multicolumn{3}{|c|}{ Normal neutrophils } & \multicolumn{3}{|c|}{ CGD neutrophils } \\
\hline & Resting* & Stimulated* & Difference & Resting* & Stimulated* & Difference \\
\hline Lactate production & 1.3 & 1.6 & 0.3 & 1.4 & 1.6 & 0.2 \\
\hline $\mathrm{CO}_{2}$ production & 0 & 0.5 & 0.5 & 0 & 0 & 0 \\
\hline Expected proton release via lactate and bicarbonate & 1.3 & 2.1 & 0.8 & 1.4 & 1.6 & 0.2 \\
\hline Measured proton release & 2.1 & 9.2 & 7.1 & 1.9 & 1.9 & 0 \\
\hline Lactate/bicarbonate-corrected proton release & & & 6.3 & & & 0 \\
\hline Oxygen consumption & 0.2 & 6.3 & 6.1 & 0.2 & 0.2 & 0 \\
\hline Ratio: $\frac{\text { Corrected proton release }}{\text { extra oxygen consumption }}$ & \multicolumn{6}{|c|}{$1.03 \pm 0.10(\mathrm{SD})$} \\
\hline
\end{tabular}

* Mean of three different preparations, assayed in parallel for all parameters, in nanomoles per minute per $10^{6}$ cells.

and protons], because it is known that stimulated neutrophils reduce extracellular cytochrome $c$ by a superoxide-dependent mechanism (16). However, addition of superoxide dismutase (SOD, Sigma Chemical Co., St. Louis, MO.; $7.5 \mu \mathrm{M}$ ) inhibited both the stimulated oxygen consumption and the stimulated proton release only about $10 \%$. Some inhibition of the oxygen consumption is to be expected (17) because dismutation of $\cdot \mathrm{O}_{2}^{-}$liberates oxygen:

$$
2 \cdot \mathrm{O}_{2}^{-}+2 \mathrm{H}^{+} \stackrel{\mathrm{SOD}}{\longrightarrow} \mathrm{H}_{2} \mathrm{O}_{2}+\mathrm{O}_{2} .
$$

If $\cdot \mathrm{O}_{2} \mathrm{H}$, or any other metabolite, were the sole source of the stimulated proton release, however, superoxide dismutase would completely inhibit this process, because all protons released by a metabolite are used again in the dismutation reaction. This was not found.

Another possible mechanism of acidification of the extracellular medium is a phosphate-hydroxyl-ion antiport, the phosphate being generated, for example, by the $\mathrm{Na}^{+} / \mathrm{K}^{+}$ATPase and/or the $\mathrm{Ca}^{2+}$ ATPase in the neutrophil membrane. This mechanism was ruled out, however, by the following experiments. Addition of the $\mathrm{Na}^{+} / \mathrm{K}^{+}$-ATPase inhibitor ouabain $(100 \mu \mathrm{M})$, the $\mathrm{Ca}^{2+}$ ionophore A23187 $(5 \mu \mathrm{M})$, or the $\mathrm{Ca}^{2+}$-transport inhibitor verapamil $(0.3 \mathrm{mM})$ did not alter the stoichiometry of the proton release vs. oxygen consumption. Moreover, in a phosphate-free medium, PMA-stimulated phosphate release was not measurable (i.e., $<0.07$ $\mathrm{nmol} / \mathrm{min}$ per $10^{6}$ cells ).

To investigate the possible existence of a proton translocator, we used several uncouplers of oxidative phosphorylation. These agents are weak acids that transport protons across (mitochondrial) membranes, thus neutralizing any proton gradient built up across these membranes (18). However, titration with 2,4dinitrophenol (10-200 $\mu \mathrm{M}) ; 4,5,6,7$-tetrachloro-triflu- oromethyl-benzimidazole $(8-50 \mu \mathrm{M})$; carbonylcyanide-m-chloro-phenylhydrazone $(10-60 \mu \mathrm{M})$; bishexafluoroacetone $(1799,10-200 \mu \mathrm{M})$, or gramicidin $(1-10 \mu \mathrm{g} / \mathrm{ml})$ did not alter the ratio of the PMA-stimulated oxygen consumption to proton release. This indicates that there is no proton transport generated by the stimulated oxygen metabolism across the plasma membranes of human neutrophils.

In conclusion, we have found a release of protons from normal, but not from CGD neutrophils during the respiratory burst. This proton release is coupled in a $1: 1$ ratio with the oxygen consumed by these cells. We did not obtain evidence that a metabolite, such as lactate, bicarbonate, perhydroxyl radicals, or phosphate causes the extracellular acidification, nor did we obtain evidence for a proton-translocating system in the plasma membranes of human neutrophils. Thus, although the extracellular proton release is predicted by our recently constructed model of the NADPH-oxidase system ${ }^{2}$ and is in accord with the observation that the cytosolic $\mathrm{pH}$ increases during the respiratory burst (19), we were unable to elucidate the mechanism of this process. We can only speculate that this rapid proton release is involved in the acidification of the phagosomes. If this proves to be true, we may expect that the lack of proton release from CGD neutrophils contributes to the bactericidal defect of these cells.

\section{ACKNOWLEDGMENT}

We express our gratitude to Dr. K. van Dam and Dr. J. A. Berden (Laboratory of Biochemistry, University of Amsterdam) for their gift of uncouplers.

${ }^{2}$ Hamers, M. N., R. Wever, M. L. J. van Schaik, and D. Roos. The NADPH-'oxidase' of human neutrophils: a multi-component plasma-membrane redox system. Manuscript submitted for publication. 


\section{REFERENCES}

1. Sbarra, A. J., and M. L. Karnovsky. 1959. The biochemical basis of phagocytosis. I. Metabolic changes during the ingestion of particles by polymorphonuclear leukocytes. $J$. Biol. Chem. 234: 1355-1362.

2. Dewald, B., M. Baggiolini, J. T. Curnutte, and B. M. Babior. 1979. Subcellular localization of the superoxideforming enzyme in human neutrophils. J. Clin. Invest. 63: 21-29.

3. Klebanoff, S. J. 1968. Myeloperoxidase-halide-hydrogen peroxide anti-bacterial system. J. Bacteriol. 95: 21312138.

4. Klebanoff, S. J., and R. A. Clark. 1978. In The Neutrophil: Function and Clinical Disorders. North-Holland Publishing Company, Amsterdam. 409-466.

5. Mandell, G. L. 1970. Intraphagosomal pH of human polymorphonuclear neutrophils. Proc. Soc. Exp. Biol. Med. 134: 447-449.

6. Jensen, M. S., and D. F. Bainton. 1973. Temporal changes in $\mathrm{pH}$ within the phagocytic vacuole of the polymorphonuclear neutrophilic leukocyte. J. Cell Biol. 56: 379-388.

7. Jaques, Y. V., and D. F. Bainton. 1978. Changes in $\mathrm{pH}$ within the phagocytic vacuoles of human neutrophils and monocytes. Lab. Invest. 39: 179-185.

8. Allen, R. C. 1979. Reduced, radical and excited state oxygen in leukocyte microbicidal activity. In Lysosomes in Biology and Pathology. J. T. Dingle, P. J. Jacques, and I. H. Shaw, editors. North-Holland Publishing Company, Amsterdam. 6: 197-233.

9. Cline, M. 1973. Mechanism of acidification of the human leukocyte phagocytic vacuole. Clin. Res. 21: 595A.

10. Weening, R. S., D. Roos, and J. A. Loos. 1974. Oxygen consumption of phagocytizing cells in human leukocyte and granulocyte preparations: a comparative study.J. Lab. Clin. Med. 83: 570-576.
11. Goldstein, I. M., D. Roos, H. B. Kaplan, and G. Weissmann. 1975. Complement and immunoglobulins stimulate superoxide production by human leukocytes independently of phagocytosis. J. Clin. Invest. 56: 1155-1163.

12. Loos, J. A., and H. K. Prins. 1970. A mechanized system for the determination of ATP + ADP, 2,3-diphosphoglycerate, glucose-1,6-diphosphate and lactate in small amounts of blood cells. Biochim. Biophys. Acta. 201: 185- 195.

13. Pachman, L. M., P. Jayanetra, and R. M. Rothberg. 1973. Rheumatoid sera and soluble complexes: nitroblue tetrazolium dye test and hexose monophosphate shunt activation. Pediatrics. 52: 823-830.

14. Cohen, H. J., M. E. Chovaniec, and S. E. Ellis. 1980 Chlorpromazine inhibition of granulocyte superoxide production. Blood. 56: 23-29.

15. Holmes, B., A. R. Page, and R. A. Good. 1967. Studies of the metabolic activity of leukocytes from patients with a genetic abnormality of phagocytic function. J. Clin. Invest. 46: 1422-1432.

16. Babior, B. M., R. S. Kipnes, and J. T. Curnutte. 1973. Biological defense mechanisms: the production by leukocytes of superoxide, a potential bactericidal agent.J. Clin. Invest. 52: 741-744.

17. Babior, B. M. 1979. Superoxide production by phagocytes. Another look at the effect of cytochrome $c$ on oxygen uptake by stimulated neutrophils. Biochem. Biophys. Res. Commun. 91: 222-226.

18. Mitchell, P. 1968. Chemiosmotic Coupling and Energy Transduction. Glynn Research Ltd., Bodmin, Cornwall, U.K.

19. Molski, T. F. P., P. H. Naccache, M. Volpi, L. M. Wolpert, and R. I. Sha'afi. 1980. Specific modulation of the intracellular $\mathrm{pH}$ of rabbit neutrophils by chemotactic factors. Biochem. Biophys. Res. Commun. 94: 508-514. 